\title{
Diagnosis and Evaluation of Conservation State of Mural Paintings in Payathonzu Temple on Bagan Heritage Site in Myanmar
}

\author{
Hwa Soo Lee', Seol Hui Kim², Kyeong Soon $\operatorname{Han}^{3, *}$ \\ ${ }^{1}$ Department of Wood and Paper Science, Chungbuk National University, Cheongju 28641, Korea \\ ${ }^{2}$ Heritage Science Center of Chungbuk National University, Cheongju 28115, Korea \\ ${ }^{3}$ Institute of Conservation of Paintings, Konkuk University, Chungiu 27478, Korea
}

\begin{abstract}
Received September 18, 2019 Revised October 07, 2019

Accepted October 13, 2019

*Corresponding author

E-mail: conservation@kku.ac.kr Phone: $+82-43-840-3677$

Journal of Conservation Science

2019;35(5):494-507

https://doi.org/10.12654/JCS.2019. 35.5.10

pISSN: 1225-5459, eISSN: 2287-9781

(c) The Korean Society of Conservation Science for Cultural Heritage

This is an Open-Access article distributed under the terms of the Creative Commons Attribution Non-Commercial License (http://creativecommons.org/ licenses/by-nc/3.0) which permits unrestricted non-commercial use, distribution, and reproduction in any medium, provided the original work is properly cited.
\end{abstract}

ABSTRACT A diagnostic investigation of the conservation state of damaged murals of the Payathonzu temple mainly indicated delamination, exfoliation, and contamination of the coloring layer; cracks and damage to the wall; and separation from gaps. In particular, vulnerabilities resulting from cracks in the wall and damage from gaps demand swift reinforcement measures. Ultrasonic testing uncovered damage caused by gaps between the base layer and plastered wall in several areas of the mural, vulnerable parts in the wall around the cracks, and considerable degradation of the physical properties where cracks and gaps were severe. Moisture measurements identified vast disparities in moisture depending on location even within a single area of the mural, and it was clear that these disparities were the result of environmental conditions such as humidity. Damage to the murals in monument 477 was the most severe, and a diagnostic of the physical properties uncovered severe physical damage to the upper part of the mural as well as to the corridor ceiling, thus presenting the need for conservation treatment utilizing scientific diagnosis as well as objective data.

Key Words Bagan, Mural painting of temple, Damage, Diagnosis, Conservation

\section{INTRODUCTION}

Bagan is located near the middle of Irrawaddy river, and was the capital of Bagan kingdom(849-1187), the first unified kingdom in the history of Myanmar. It is known that about 5,000 Buddhist pagodas were established from the 11th century to the 13th century. A large number of murals were painted on the wall inside the pagodas, creating a repository of Buddhist mural paintings. After the two big earthquakes of 7.0 Mw (moment magnitude scale) and $6.8 \mathrm{Mw}$, which also hit the Bagan area in Myanmar respectively in 1975 and
Aug. 2016, significant damage was caused to many temples and Buddhist pagodas. A total of 389 temples were damaged and structural damage to the building and mural paintings occurred in 165 temples.

The survey conducted in 2017 to identify the extent and type of damage to the mural paintings found that severe structural damage occurred in mural paintings due to earthquakes. In addition, it was found that the characteristics of materials used for mural paintings and aging caused by the surrounding environment and reinforcement materials and fixing agents used in the past also contributed to the damage. 
Currently, conservation treatment is required since damages were found on the walls, the painting layers, and the previously repaired parts in the murals in Payathonzu temple. For the murals in a poor conservation condition, speedy reinforcement treatment should be made; however, for more persistent and more stable conservation, a systematic process should preferentially be built for the mural painting conservation treatment. Thus, this study would propose the preparation of a basic plan for the stable conservation treatment of the damaged murals based on the results of the investigation and diagnosis of the conservation condition of the murals in Payathonzu temple.

\section{THE STATUS OF TARGETS AND RESEARCH TREND}

\subsection{The status of targets}

The Payathonzu temple consists of three temples(\#477, \#478, \#479) in a row(Figures 1 and 2). The Payathonzu temple features three pathos, and the outside is decorated with stuccos, but now these elements are almost lost. The front faces north and consists of four doors.

The mural paintings in Payathonzu temple were damaged by earthquake that hit the area in 1975. A dedicated team composed of government officials related to construction conducted repair of buildings and added mural paintings under the Yangon government. It was reported that the peeled off are near the mural painting was treated with cement used for construction, and the peeled off mural paintings and wall structures were filled and reinforced with brick powder, lime, sand and cement(Figure 3).

It seems that experts in Myanmar conducted consolidation treatment with PVAs before ICCROM was requested by the Myanmar government to conduct survey in the early 1980s(ICCROM, 1983; 1985). An official from Bagan office said that a mixture of PVAc and toluene diluted to 10 to $15 \%$

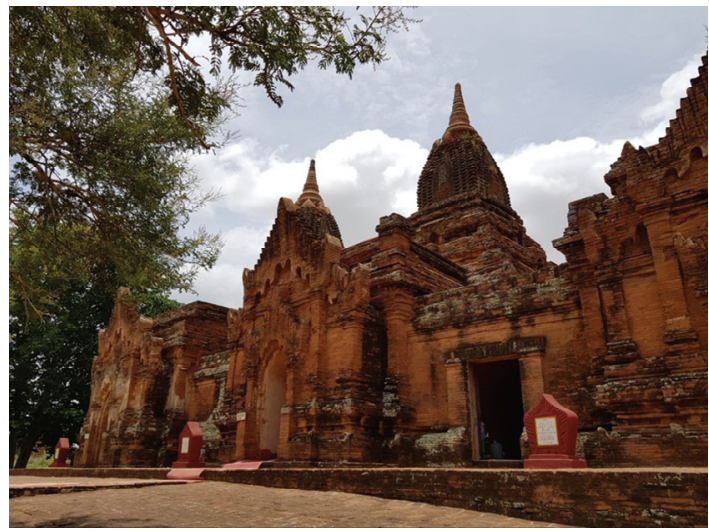

Figure 1. Front view of Payathonzu temple.

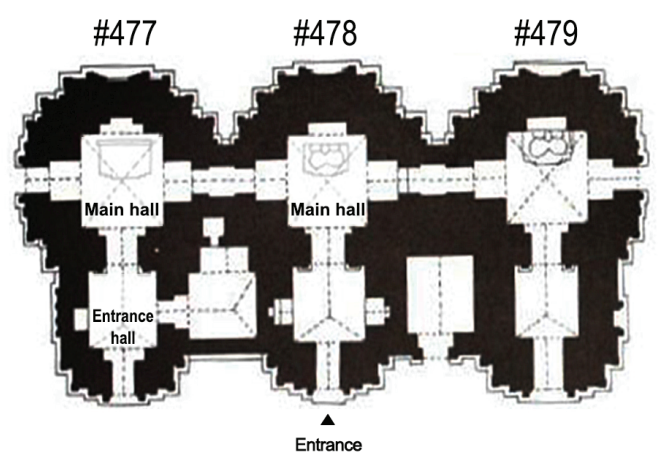

Figure 2. Plan of Payathonzu temple.

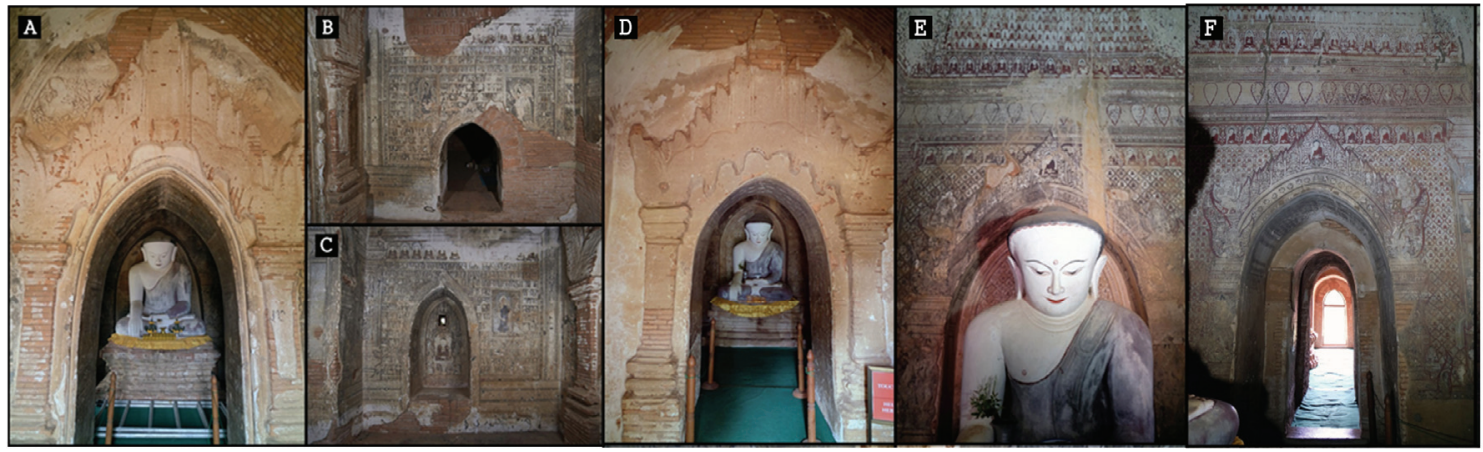

Figure 3. Image of status in Payathonzu temple. (A) \#477 entrance hall to main hall, (B) \#477 entrance hall-east side, (C) \#477 entrance hall-west side, (D) \#478 entrance hall to main hall, (E) \#478 main hall-north side, (F) \#478 main hall to \#479 main hall. 
was used in 1978 as reinforcement material to conserve the painting layer.

The damage caused by the 2016 earthquake was not that severe, but during the immediate conservation diagnosis conducted immediately after the earthquake, it was diagnosed that Payathonzu temple should undergo conservation treatment. Officials in Bagan office reinforced the rear side of the main hall of \#477 and the top of the passage that links $\# 477$ and \#478, which were cracked and peeled off, using lime and sand and used thinner mixed with Paraloid B-72 on some painting layers of the wall(Korea Culture Heritage Foundation et al., 2018).

The current Payathonzu mural paintings have suffered several damages like cracking, separation between layers, peeling off and exfoliation. In the past, repair of mural paintings was conducted several times, but the repairs led to cracks in the area or separation from wall structure. In some cases, the fixing agents used in the past made the painting too shiny or led to fading or peeling off together with the painting layer.

\subsection{Research trend}

Many studies have been conducted regarding the conservation of temple murals in the Bagan, Myanmar. Regarding reports and papers on research results, starting with the investigation report, 'Mission report-technical assessment for the association of the primary painting and techniques at Pagan,' for 16 temples(including the Payathonzu) investigated(ICCROM, 1982), approximately 40 books of literature have been investigated.

In particular, 10 reports published between 1985 and 1994, describe the conservation treatment process of the murals in the Mynkaba Kubyaukgyi temple and the Lokahteick Pan temple, which are regarded as the major temples of the Bagan ruins(ICCROM, 1985; UNESCO, 1994). Studies related to the conservation of the Bagan murals by Korean researchers include the case of conservation treatment of Bagan murals 12th century (Lee and Ahn, 2008), and the study of the Lokate Ikpan temple in Bagan (Joo, 2016).

The case of research in Korea about the diagnosed murals, includes the mural paintings of Muwisa temple in Gangjin (Chae et al., 2006), Myeongbujeon hall of Jikjisa temple in Gimcheon(Lee et al., 2012), Daeungjeon hall of Jikjisa temple in Gimcheon(Lee et al., 2018a), Buseoksa temple in Yeongju(Haisung Cultural Heritage Conservation, 2019), and studies related to mural production techniques include making techniques of mural paintings in Bongjeongsa temple(Jeong et al., 2008), mural paintings of tomb in Daegaya period(Lee et al., 2014), material characterization of mural paintings in Joseon dynasty(Lee, 2016), manufacturing techniques of bracket mural paintings in Daeungbojeon hall at Naesosa temple(Lee et al., 2018b).

\section{RESEARCH METHODS}

\subsection{Categorization of the subject of investigation}

The main target objects were the murals of \#477, \#478, at the Payathonzu temple of Myanmar, and the classification is as follows(Table 1, Figure 4). As for directions, the entrance to the temple is south, and the back side of the statue of Buddha is north.

\subsection{Diagnosis and investigation}

\subsubsection{Investigation of the structural layer of murals}

Prior to diagnosis and investigation, a basic investigation

Table 1. The list of investigation area of mural paintings on the Payathonzu temple

\begin{tabular}{cll}
\hline Area No. & \multicolumn{1}{c}{ Area name } & \multicolumn{1}{c}{ Direction of wall } \\
\hline 1 & $\# 477$ entrance hall & east, west side \\
\hline 2 & $\# 477$ main hall & east, west, north, south side \\
\hline 3 & $\# 478$ main hall & east, west, north, south side \\
\hline 4 & $\# 477$ passage of entrance to main hall & east $1 \cdot 2$, west $1 \cdot 2$, arch \\
\hline 5 & $\# 477$ passage of west window & north, south \\
\hline 6 & $\# 478$ passage of entrance to main hall & east $1 \cdot 2$, west $1 \cdot 2$, arch \\
\hline 7 & passage of $\# 477$ to $\# 478$ & north $1 \cdot 2 \cdot 3 \cdot 4 \cdot 5$, south $1 \cdot 2 \cdot 3 \cdot 4, \operatorname{arch~} 1 \cdot 2$ \\
\hline 8 & passage of $\# 478$ to $\# 479$ & north, south \\
\hline
\end{tabular}



.

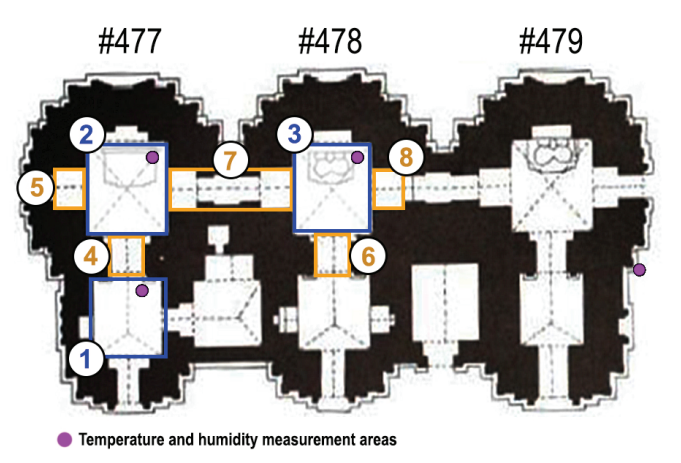

Figure 4. Separation for investigation area of Payathonzu temple.

was first conducted on the wall layer that comprises the murals. As for the structural layers, the support layer, middle layer and finishing layer of the wall were investigated for their status of composition, and the thickness of the middle layer and the finishing layer were measured, respectively. The results of investigation into the structural layers were made into drawings, using illustrations together with photographic data records.

\subsubsection{Investigation of temperature and humidity}

Temperature and humidity meters(174H1, Testo, DEU) were installed at four places in and outside of the temple, \#477 entrance hall and main hall and \#478 main hall during the field survey period(Aug. 1 to 3, 2018, Oct. 13 to 17 , 2018) to monitor the environment in and outside of Payathonzu temple. Accordingly, temperature and humidity data were collected on an hourly basis. The temperature and humidity were measured, and data was organized by the dates. Measurement of the inner and external temperature and humidity conducted from Aug. 1 to 3 and Oct. 13 to 17 was turned into graph format and the average temperature and humidity were calculated.

\subsubsection{Analysis of moisture content}

Moisture content of the wall was measured to investigate the distribution of moisture level of the mural paintings and the impact of moisture on the paintings. It was measured using dielectric moisture meter(testo 616, Testo, DEU). The measuring interval was $200 \mathrm{~mm}$.

\subsubsection{Ultrasonic examination}

Ultrasound examination was conducted on the surface of mural paintings through Ultracon-170(MKC Korea, KOR). The data was used to produce the contour map of relative velocity distribution of the mural paintings' surface. Small-sized ultrasonic measurement probes $(54 \mathrm{kHz})$ were used, and the investigations were performed with voltage $1,200 \mathrm{~V}$, distance $150 \mathrm{~mm}$ between probes, and the indirect measurement method.

\subsubsection{Infrared and ultraviolet graph}

Infrared and ultraviolet imaging was used to find out the specific characteristics of mural paintings such as under drawing, paint-over or previous conservation treatment, which cannot be seen with visual inspection. IR lamp and infrared camera(Fujifilm X-T1, Fujifilm, JPN) with IR filter were used for infrared imaging. UV-B Test(Model-Q-22B /F, Spectroline, Co., USA) and Fuji DSLR were used for ultraviolet imaging.

\subsubsection{Description of conservation state}

The recording of the state of damage was based on visual inspection and the main focus was on the painting layer. In addition, digital microscopic examination was conducted to examine the detailed condition. The conservation state of mural paintings was described in two parts: type of damage and state of damage. Type of damage included crack, exfoliation and delamination of painting layer, uplift of finishing layer, contamination, water leak, artificial damage, biological damage, and previous repair material. The state of damage is described in details by presenting the current state of each hall and passage including direction information.

\section{RESULTS AND CONSIDERATIONS}

\subsection{Structural layer of murals}

It has been confirmed that the structure of the mural is composed of a wall made of piled bricks with several layers of lime plaster on top, and the painting over the top.

The middle wall, which forms the ground layer, shows the thickness of average 15-20 mm, albeit slightly varying with its locations. Although it is found that it consists of 2-3 layers, it was plastered more times than them, and rather thick layers are occasionally found, too. As for the finishing layer, it is found that similar conditions of kneading to the middle layer were used, and the layer has the thin thickness 


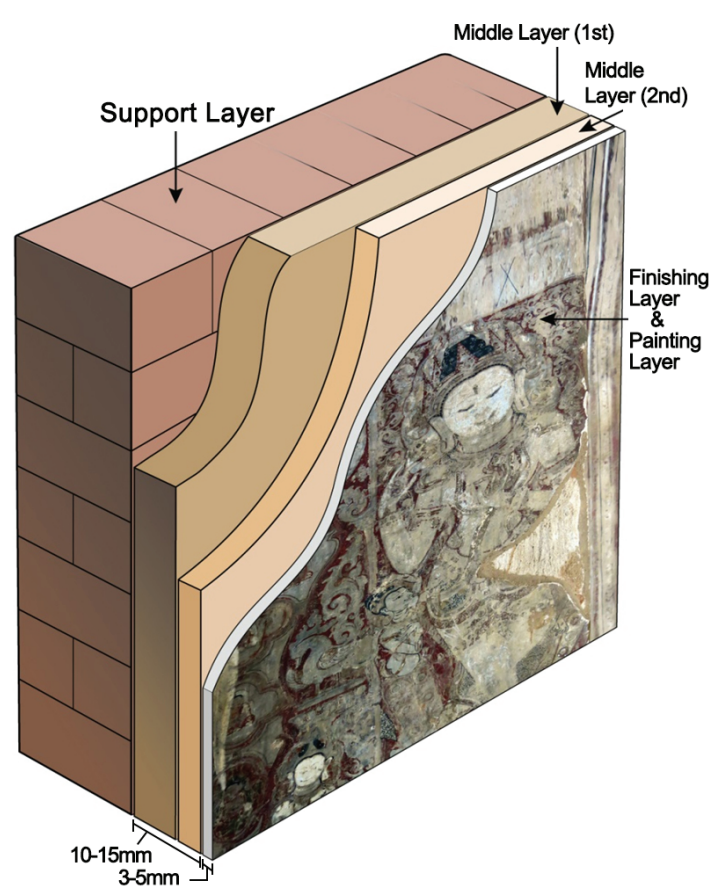

Figure 5. Diagram of structure and layers of mural painting of Payathonzu temple.

of about 3-5 mm, though also varying with locations. As for the painting layer, it is found that overall it was painted considerably thin, though varying with pigments used. The thickness of the painting layer varies depending on the pigment layer used, but it is generally found to be colored on a thin layer(Figures 5 and 6).

Through the existing research results, it has been determined that the walls of the Payathonzu are built of lime plaster, which is mainly comprised of calcium carbonate $\left(\mathrm{CaCO}_{3}\right)$. Additionally, it is reported that the wall was made by mixing soil materials such as sand and clay into lime paste. Also, according to the analysis of grain size conducted on the particles of the wall, grains smaller than silt, which correspond to the size of lime, account for $8 \%$ of the total. Thus, even if silt and clay were to be excluded, it can be confirmed that the grains fit the mortar condition, which is high in sand and extremely low in lime(Korea Culture Heritage Foundation et al., 2018).

\subsection{Temperature and humidity}

In August, the temperature within the entrance hall was average $30.8^{\circ} \mathrm{C}$, and difference between the highest temperature

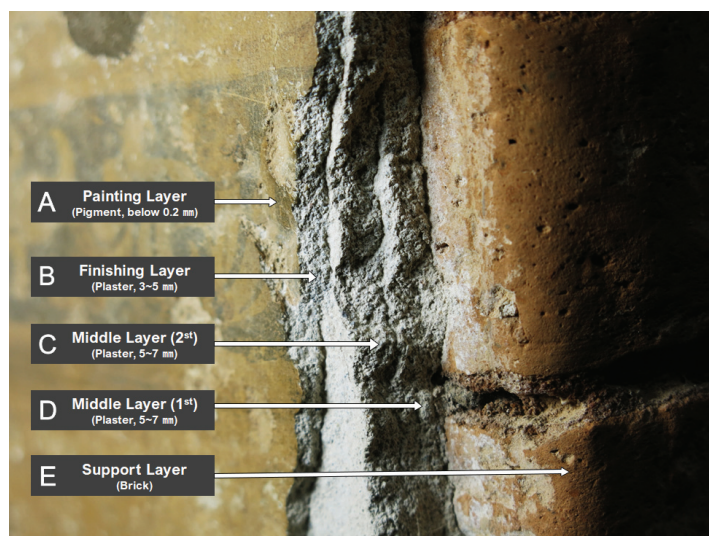

Figure 6. The structure of mural painting in Payathonzu temple. (A) Painting layer over the finishing layer (below $0.2 \mathrm{~mm})$, (B) Finishing layer of thin lime plaster $(3-5 \mathrm{~mm})$, (C) Second middle layer (3-5 mm), (D) First middle layer(5-7 mm), (E) Support layer made of piled bricks.

and the lowest temperature was $3.0^{\circ} \mathrm{C}$. The relative humidity was average $64.9 \%$, and it was found that difference between the highest humidity and the lowest humidity was $9.2 \%$. In October, it was found that the average temperature was $28.1^{\circ} \mathrm{C}$, and the difference between the highest temperature and the lowest temperature was $2.4^{\circ} \mathrm{C}$. The relative humidity was average $80.8 \%$, and difference between the highest humidity and the lowest humidity was $15.0 \%$ (Table 2 and Figure 7).

To sum up the results, it is judged that entrance hall of \#477 is considerably affected by external environment. To compare it with other measurement areas, it was found that its differences between the highest and lowest temperature and humidity were greatest. According to the results of measurement in August, the relative humidity rises during hours from evening to early morning when temperature drops, but is low during daytime, showing the opposite aspect. However, in October that is the latter half of rainy season, the relative humidity is lowest $70.2 \%$ and highest $85.2 \%$, maintaining the humid condition of average $80.8 \%$ all day long. From this, it can be seen that more humid environment is maintained in August, early rainy season, than in October, the latter half of rainy season. The moisture contents of the murals also showed noticeably wide variations according to locations, and it was found that loss and damage were severe in the surfaces of murals on which pictures were painted.

\#477 main hall in August, it was found that relative humidity dropped during daytime and showed the opposite 
Table 2. Results of temperature and humidity measurement

\begin{tabular}{cccccccc}
\hline \multirow{2}{*}{ Area } & \multicolumn{2}{c}{ Time period } & \multicolumn{3}{c}{ August } & \multicolumn{3}{c}{ October } \\
\cline { 3 - 8 } \#477 entrance hall & & Minimum & Maximum & Average & Minimum & Maximum & Average \\
\hline \multirow{2}{*}{ \#477 main hall } & ${ }^{\circ} \mathrm{C}$ & 29.7 & 32.7 & 30.8 & 27.1 & 29.5 & 28.1 \\
\cline { 2 - 8 } & $\% \mathrm{RH}$ & 60.0 & 69.2 & 64.9 & 70.2 & 85.2 & 80.8 \\
\hline \multirow{2}{*}{ \#478 main hall } & ${ }^{\circ} \mathrm{C}$ & 29.2 & 31.2 & 30.0 & 28.1 & 29.1 & 28.6 \\
\cline { 2 - 9 } & $\% \mathrm{RH}$ & 62.2 & 71.1 & 67.5 & 70.5 & 77.0 & 73.8 \\
\hline \multirow{2}{*}{ Outside } & ${ }^{\circ} \mathrm{C}$ & 29.2 & 31.3 & 30.1 & 27.6 & 29.1 & 28.4 \\
\cline { 2 - 9 } & $\% \mathrm{RH}$ & 64.9 & 73.5 & 69.7 & 70.8 & 80.5 & 76.9 \\
\cline { 2 - 9 } & ${ }^{\circ} \mathrm{C}$ & - & - & - & 22.3 & 40.0 & 27.6 \\
\hline
\end{tabular}
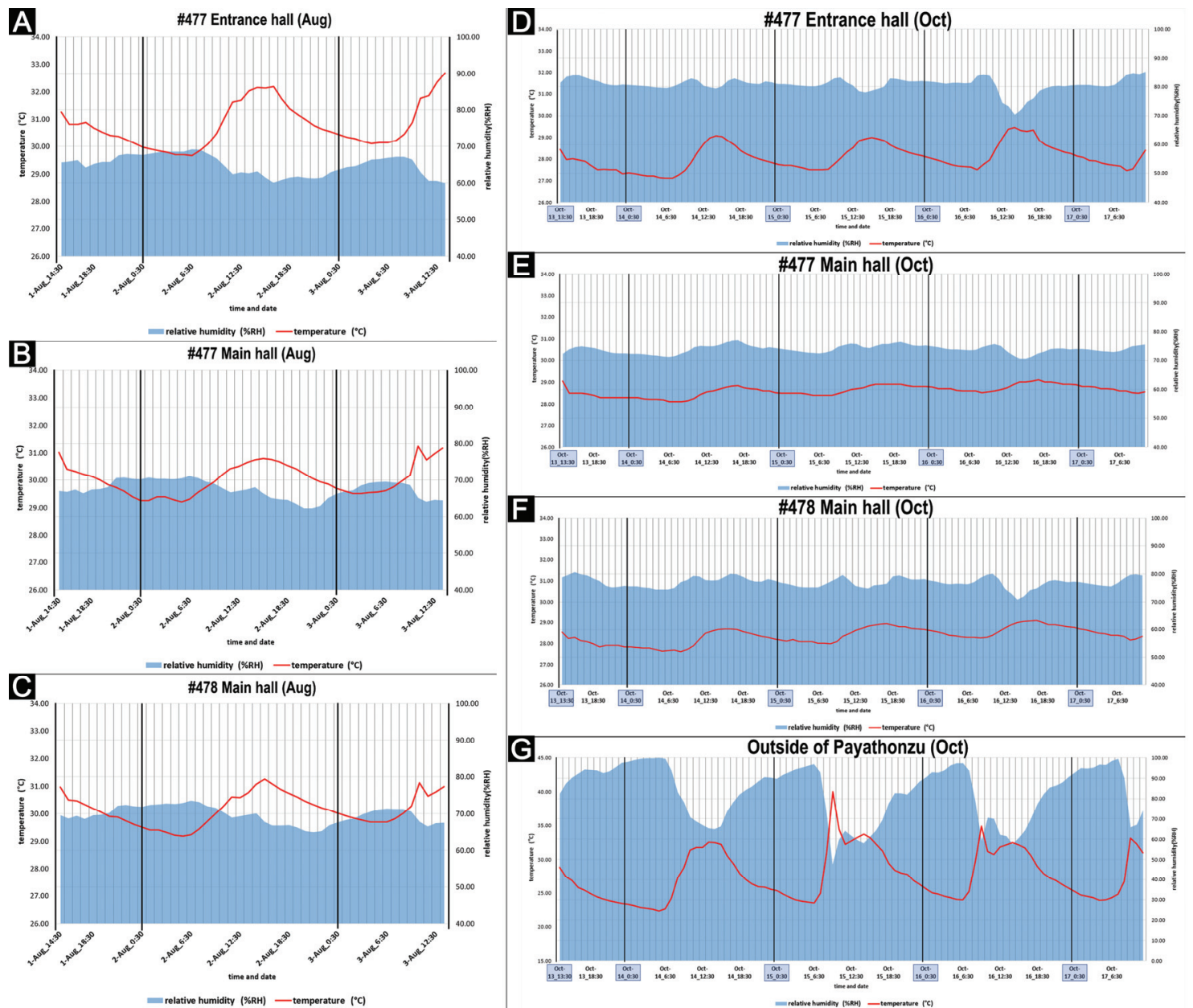

Figure 7. Temperature and humidity results of Payathonzu temple. (A) Aug. \#477 entrance hall, (B) Aug. \#477 main hall, (C) Aug. \#478 main hall, (D) Oct. \#477 entrance hall, (E) Oct. \#477 main hall, (F) Oct. \#478 main hall, (G) Oct. Outside of Payathonzu.

aspect during night, similarly to the entrance hall of $\# 477$. The results of October, however, show the highest value of relative humidity as well at the highest point of daily temperature. And the highest points of temperature and humidity appeared during a period of $3 \mathrm{pm}$ to $5 \mathrm{pm}$. In comparison, the results of measuring the external temperature 
of Payathonzu show that it recorded the highest value during a period of $10 \mathrm{am}$ to $3 \mathrm{pm}$, and the relative humidity shows the lowest point at that time period. Building temperature rises during the time period and drops after then, and thus hot temperature is contained within the building.

In the case of the main hall of \#478, it shows aspects of variation similar to the main hall of $\# 477$, but is characterized by higher average humidity by about $3 \%$. It is judged that this is attributed to its condition that it has only one passageway at the entrance, compared with the structure of $\# 477$ and \#479 where the front side and the lateral side are opened towards the outside. This is circumstantially demonstrated by the results that its mural moisture content is higher than $\# 477$.

Repeated moisture variation makes vulnerable the relics having porosity and softness like murals, and acts as a factor sensitive to changes in mural structure and materials in the long term. Particularly, in the case of the wall of Payathonzu that is directly exposed to ambient air continuously and is adjacent to the ground, it may show irregular moisture distribution, which is also confirmed by the results of investigation into the moisture content of the wall. Given the locational characteristics found from the examination of temperature and humidity, and the results of measuring the moisture content, it is found that the murals are not maintained under stable conditions for preserving environment.

\subsection{Moisture measurement}

In terms of the average moisture level inside the mural paintings in Payathonzu temple, the value was the highest at the passage from \#477 main hall to \#478 main hall. In terms of minimum value, \#478 passage of entrance to main hall showed the highest value while \#477 passage from entrance hall to main hall showed the lowest value(Table 3).

The average, minimum and maximum values for the

Table 3. Results of moisture measurement

\begin{tabular}{cccc}
\hline Area No. & Average & Minimum & Maximum \\
\hline 1 & 4.1 & 0.7 & 16.9 \\
\hline 2 & 2.9 & 1.0 & 7.1 \\
\hline 3 & 2.3 & 0.2 & 7.6 \\
\hline 4 & 2.8 & 1.7 & 4.0 \\
\hline 5 & 3.7 & 1.5 & 14.6 \\
\hline 6 & 3.4 & 2.0 & 5.7 \\
\hline 7 & 5.6 & 2.0 & 20.1 \\
\hline 8 & 4.6 & 1.4 & 16.9 \\
\hline
\end{tabular}

Unit: \%.

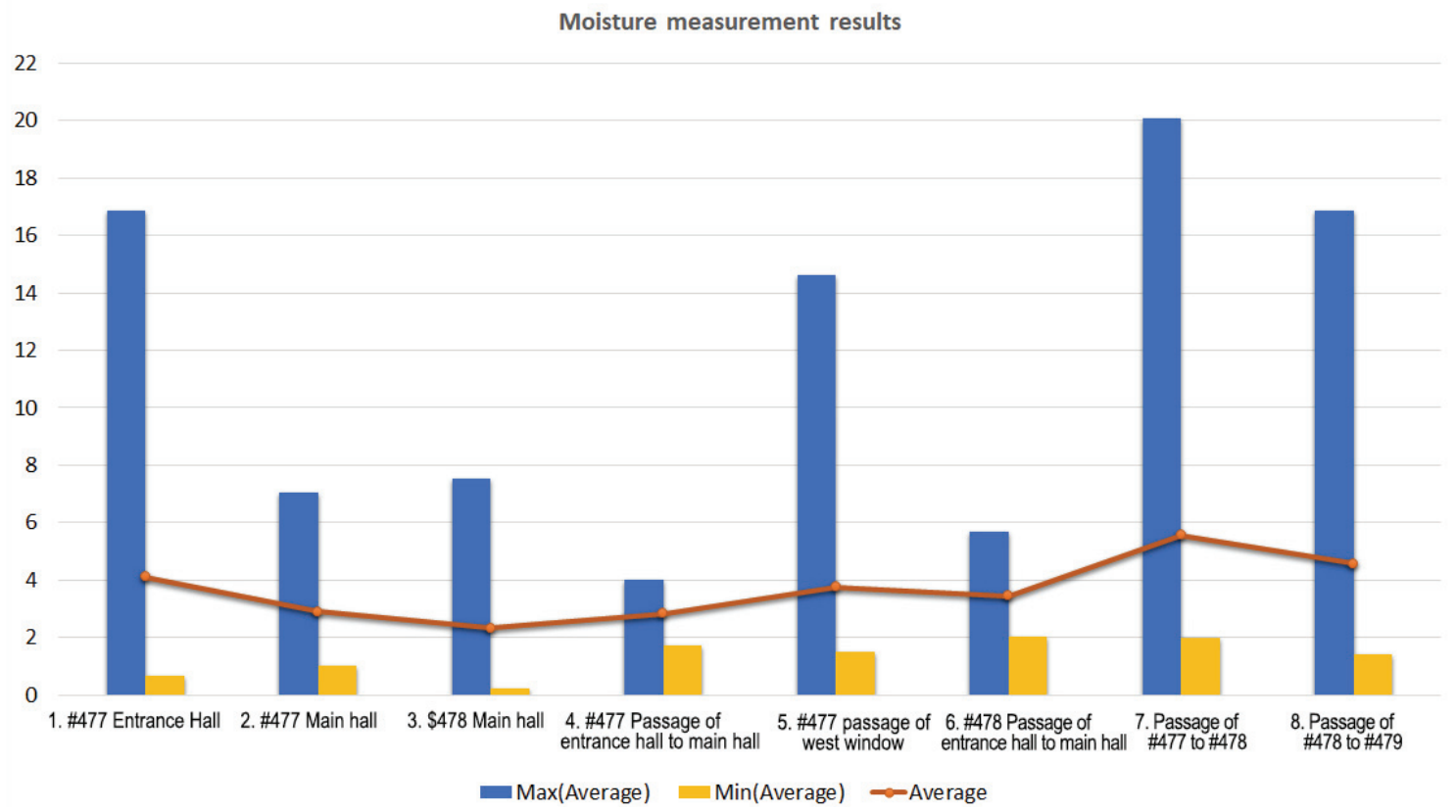

Figure 8. Moisture measurement results. 
A
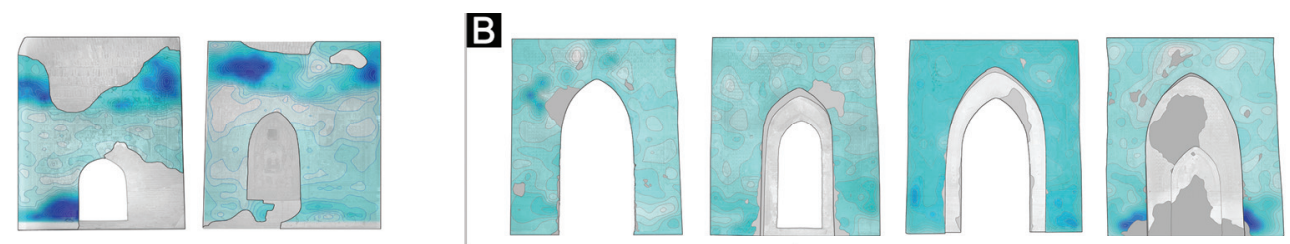

C
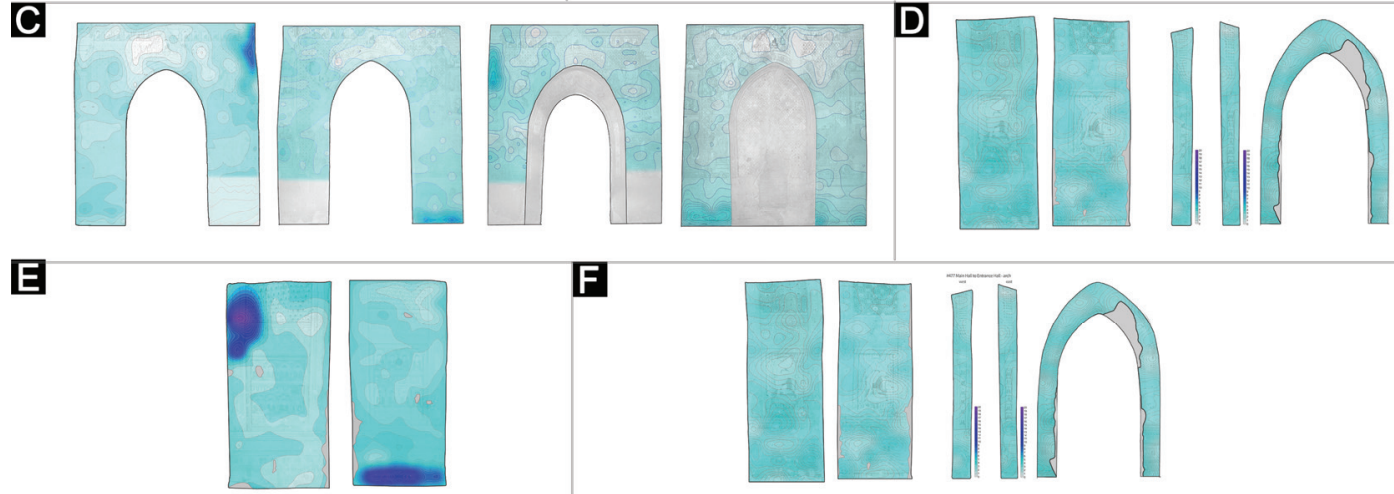

G
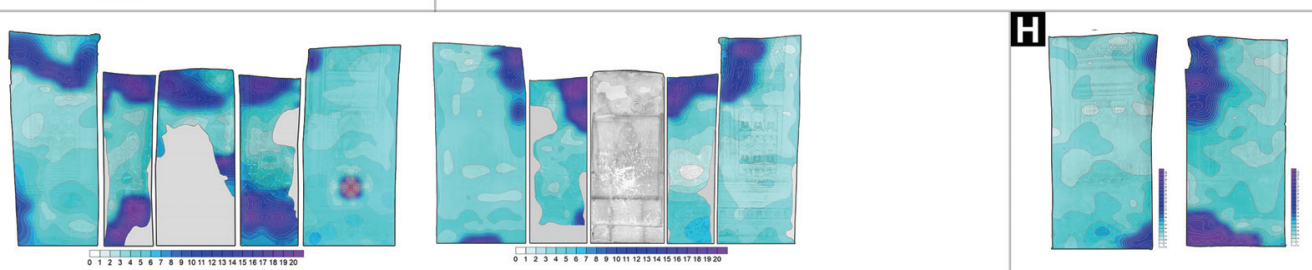

Figure 9. Image mapping of moisture measurement. (a) \#477 entrance hall east and west, (b) \#477 main hall, east, west, south, north, (c) \#478 main hall, east, west, south, north, (d) \#477 passage of entrance to main hall, east 1, west 1, east 2, west 2, arch, (e) \#477 passage of west window, north, south, (f) \#478 passage of entrance to main hall, East 1 , west 1 , east 2, west 1 , arch, (g) passage of $\# 478$ to $\# 479$, north, south, (h) passage of $\# 477$ to $\# 478$, north $1 \cdot 2 \cdot 3 \cdot 4 \cdot 5$, south $1 \cdot 2 \cdot 3 \cdot 4$

passage from \#477 main hall to \#478 main hall were high. The average, minimum and maximum values were relatively high for the passage from \#478 main hall to \#479 main hall. The passage from hall to hall showed high moisture levels while the wall located behind the main hall showed relatively low moisture level(Figure 8).

Compared to the $\# 477$ main hall and entrance hall exhibited a significantly higher moisture ratio and a significant variation in the ratio. The external environment is causing significant changes in humidity. In particular, the degree of damage tends to be severe in areas where the moisture ratio showed large variation.

The variation in the moisture ratio of the walls may be connected to the conservation status of the murals. Given the properties of material and the deterioration map of the mural, the moisture ratio may be connected to the lifting and washing away of the wall, and damages such as peeling off and exfoliation of the painting layer.

The moisture ratio was high in the passage, which is a relatively small area compared to the main hall, and the ratio was somewhat higher in the \#478 main hall than in the \#477 main hall. Such tendency may be connected to the humidity measured inside the temple(Figure 9).

\subsection{Ultrasonic examination}

The distribution of ultrasound speed was mapped for areas where the properties are not in good quality due to crack, damage or peeled off wall structure. Based on the results of all measurements, the maximum ultrasound speed was measured to be $891 \mathrm{~m} / \mathrm{s}$, and the minimum ultrasound speed was measured to be $105 \mathrm{~m} / \mathrm{s}$ (Table 4, Figure 10).

Overall, high ultrasonic speed was detected at the main hall of \#478, and the entrance hall(west) of \#477 showed the 
lowest ultrasonic speed. According to recent research findings, in the case of soil murals painted with a mixture of red clay and sand, low speed values of about 100-150 m/s are reported, and are interpreted as measurement values obtained due to heterogeneous wall media conditions and pores. In general, it is found that low speed values of $150 \mathrm{~m} / \mathrm{s}$ or below are measured at sections in murals containing lots of sand, in which crack or delamination is identified. In the case of the murals of Payathonzu temple as well, the existing diagnosis and interpretation are followed under the condition of walls of high sand content.

In terms of the minimum value, \#478 passage from entrance hall to main hall showed the highest figure while passage from \#478 main hall to \#479 main hall showed the lowest figure. In terms of the maximum value, \#477 entrance

Table 4. Results of ultrasonic velocity values

\begin{tabular}{cccc}
\hline Area No. & Average & Minimum & Maximum \\
\hline 1 & 374 & 117 & 891 \\
\hline 2 & 374 & 101 & 746 \\
\hline 3 & 397 & 124 & 854 \\
\hline 4 & 320 & 146 & 615 \\
\hline 5 & 248 & 112 & 505 \\
\hline 6 & 329 & 129 & 737 \\
\hline 7 & 282 & 118 & 550 \\
\hline 8 & 299 & 105 & 573 \\
\hline
\end{tabular}

Unit: $\mathrm{m} / \mathrm{s}$. hall showed the highest value while \#477 passage of west window showed the lowest value. The order of measured values from the highest to the lowest value is shown in the table 4. Overall, the ultrasound speed was high in \#478 main hall while the \#477 passage of west window) showed the lowest ultrasound speed.

The average values of the passage were lower than those of the main hall or entrance hall. This is attributable to the speed of the upper vault of the passage, and most of the upper part of the passage exhibit drastically lower ultrasonic values, as a result of the cracks, peeling off, and lifting of the wall. As for parts of lowered physical properties detected by ultrasonic speed values, it can be seen that damaged portions of walls like upper side of \#477 entrance hall are mostly matched in the assessment of damage state. In addition, low ultrasonic speed values are measured at portions repaired with mortar like \#477 main hall and \#478 main hall, which shows that the structure is vulnerable because the inside was not filled though a crack was filled. And as passage area and upper vault parts, there were parts where high moisture contents were identified at portions of low ultrasonic speed values. In these portions, physical damage such as finishing layer separation was mostly occurring. The difference of ultrasonic values may vary within a single mural, with complex layers and composition of various materials, depending on various factors such as density,

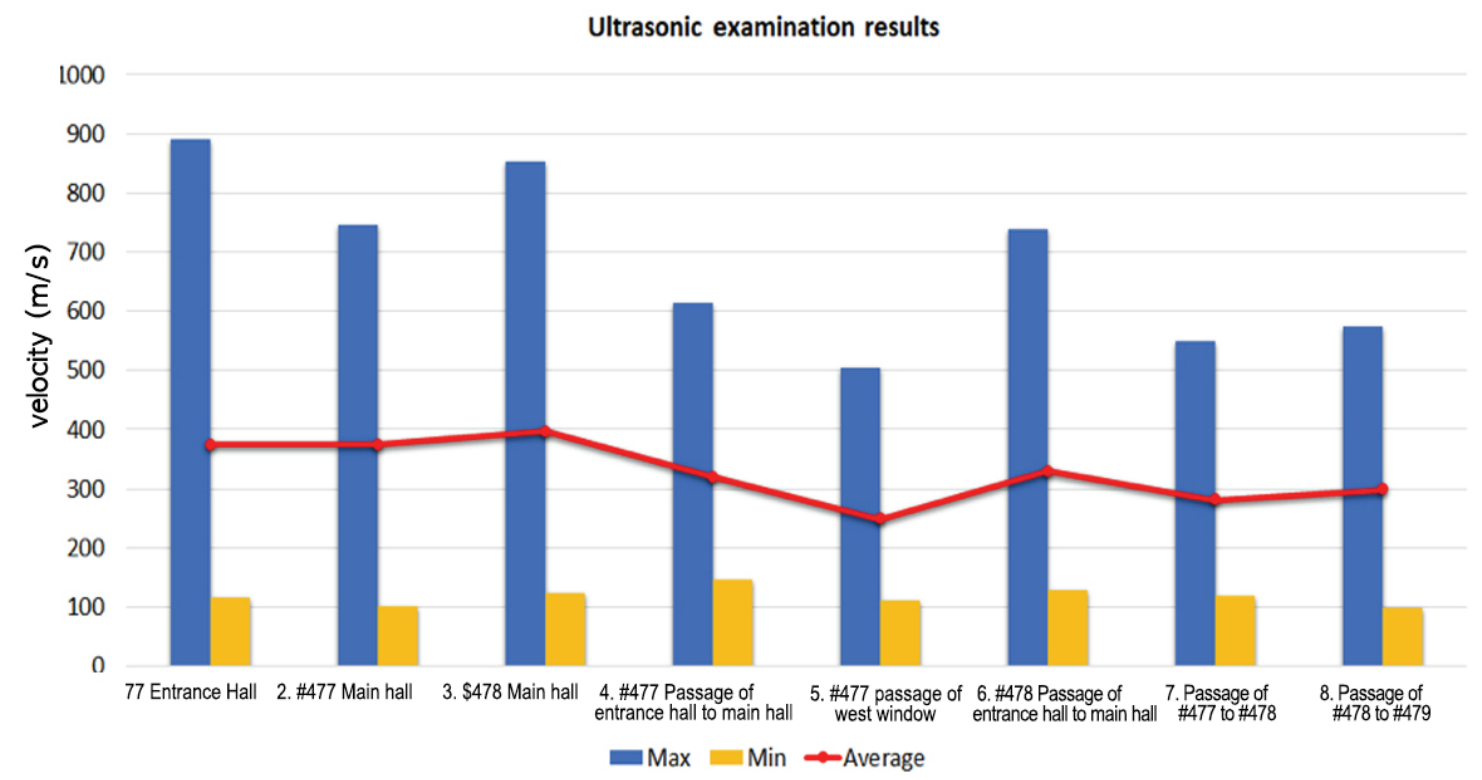

Figure 10. Ultrasonic examination results. 


\section{A}
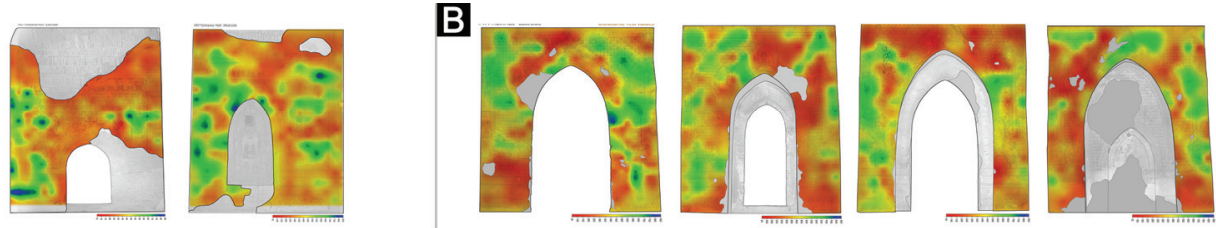

\section{C}
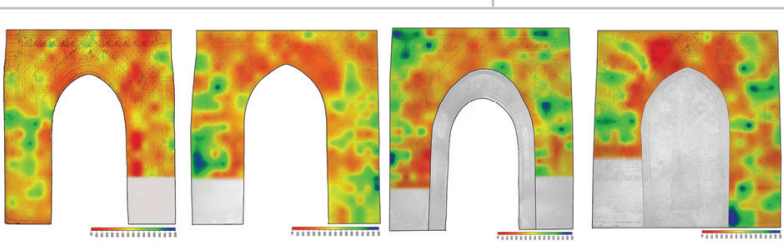

D
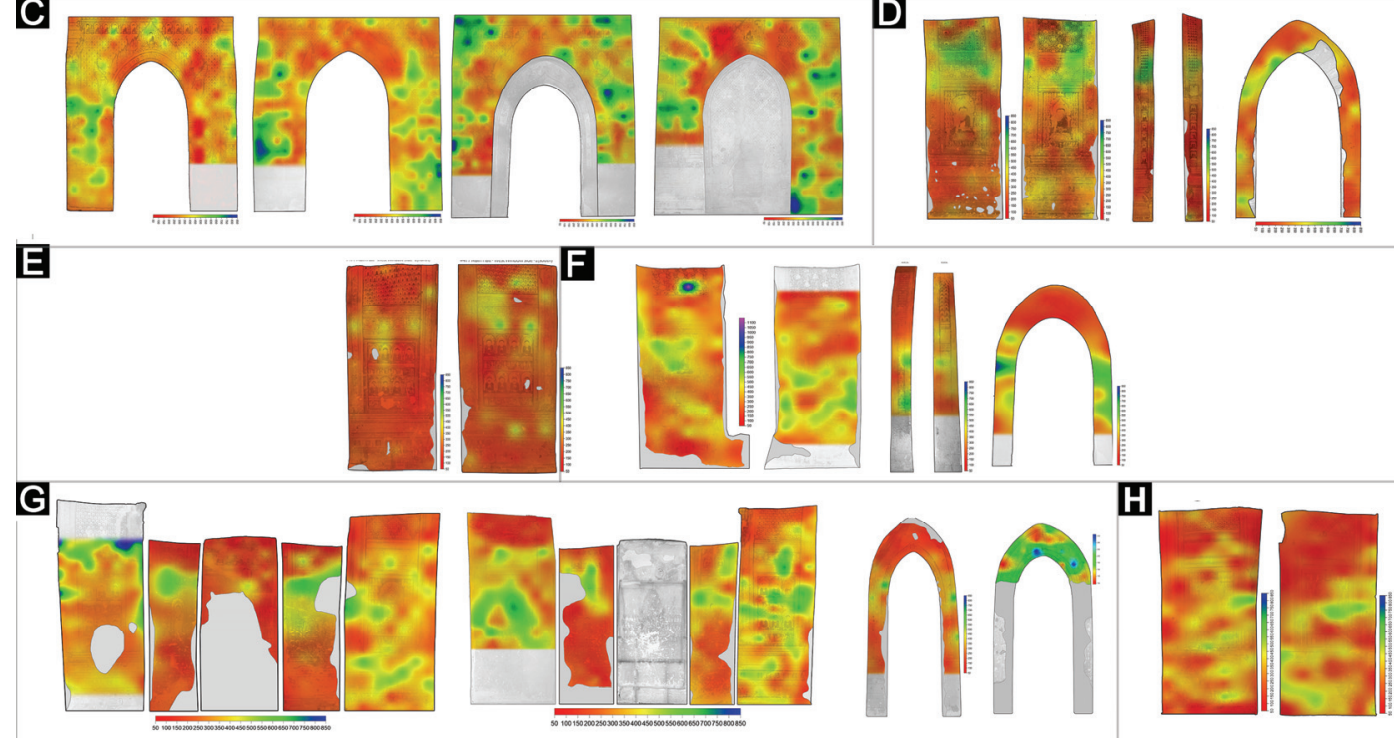

Figure 11. Image mapping of ultrasonic test. (a) \#477 entrance hall east and west, (b) \#477 main hall, east, west, south, north, (c) \#478 main hall, east, west, south, north, (d) \#477 passage of entrance to main hall, east 1, west 1 , east 2, west 2, arch, (e) \#477 passage of west window, north, south, (f) \#478 passage of entrance to main hall, east 1, west 1, east 2, west 1, arch, (g) Passage of \#478 to \#479, north, south, (h) Passage of \#477 to \#478, north $1 \cdot 2 \cdot 3 \cdot 4 \cdot 5$, south $1 \cdot 2 \cdot 3 \cdot 4$, arch 1 , arch 2 .

thickness of the wall, cracks, status of lifting and the overall conservation status of the mural. As such, the ultrasonic inspection may not be the absolute factor that best represents the physical properties of the mural. However, when diagnosing artifacts under similar conditions with the same measurement conditions, the values may be used as comparative data to assess different areas within the wall surface, based on their respective values.

Therefore, ultrasonic inspection of the mural may provide objective data on the areas that require preservation treatment, such as cracks and lifting of the wall. In particular, the results of the inspection may be used as reference data when it comes to reinforcing vulnerable areas of the wall, such as the upper part of the wall or vault of the passage(Figure 11).

\subsection{Optical survey}

As a result of the infrared inspection, it was possible to identify rough sketches or images that have been painted over in parts of the areas. In particular, a clearer visual of images from the painting layer that have been contaminated were obtained. Also, an infrared response was used to identify the underlining that was not visible to the naked eye in the form of the edge figure on the south side of \#478 main hall(Figure 12).

The ultraviolet inspection confirmed various information that was unavailable under the visible rays. Through the fluorescence reaction, areas that had been painted over as well as areas damaged from discoloration were clearly identified. In particular, traces of repair materials - presumed to be PVAc - and excess application of such materials also were revealed. In addition, areas of similar colorations were clearly identified(Figure 13).

If cleaning is carried out, the image identified through infrared irradiation can be referred to as useful data, allowing the mural to be restored more clearly. Also, damaged areas in the painting layer and the damage caused by synthetic resins, as identified through the ultraviolet inspection, can serve as useful information in the conservation process, such 

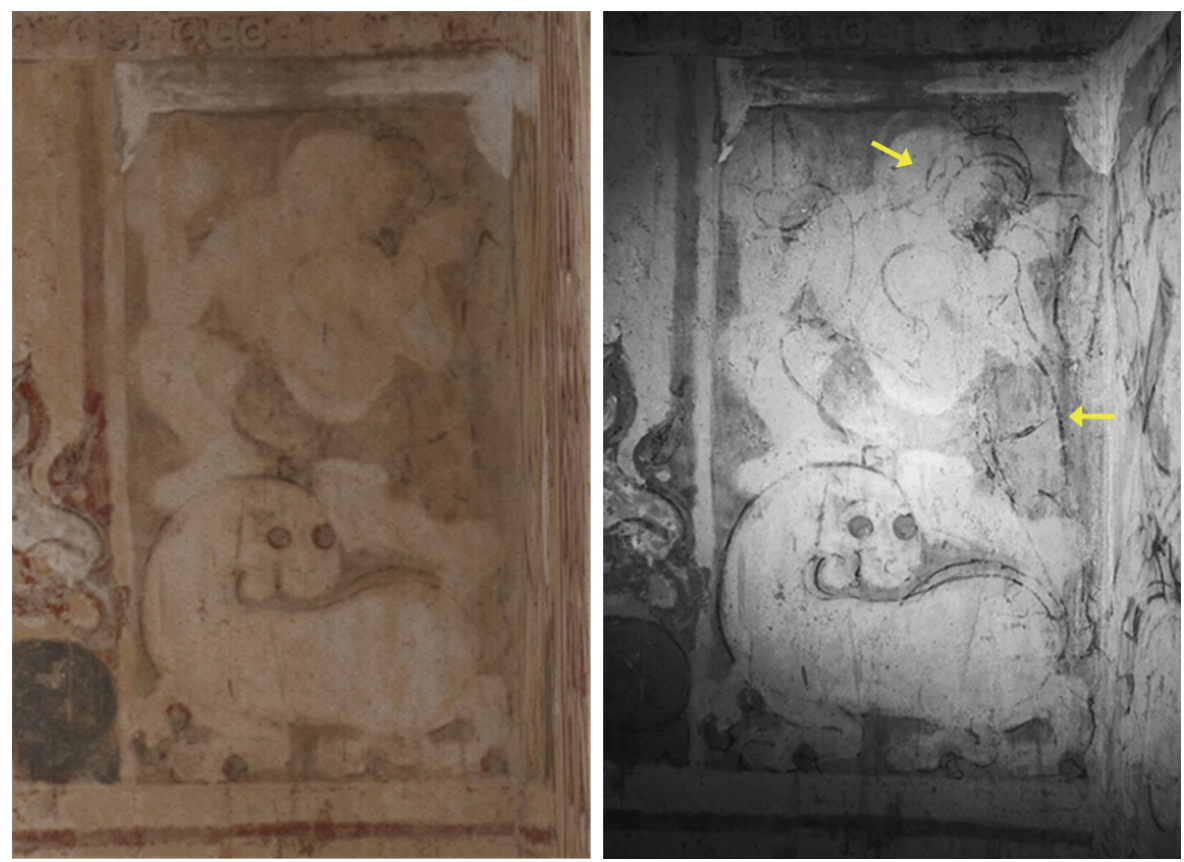

Figure 12. Images of the visible light(left) and the infrared light(right) and underpainting detected(\#478 main hall-south side).
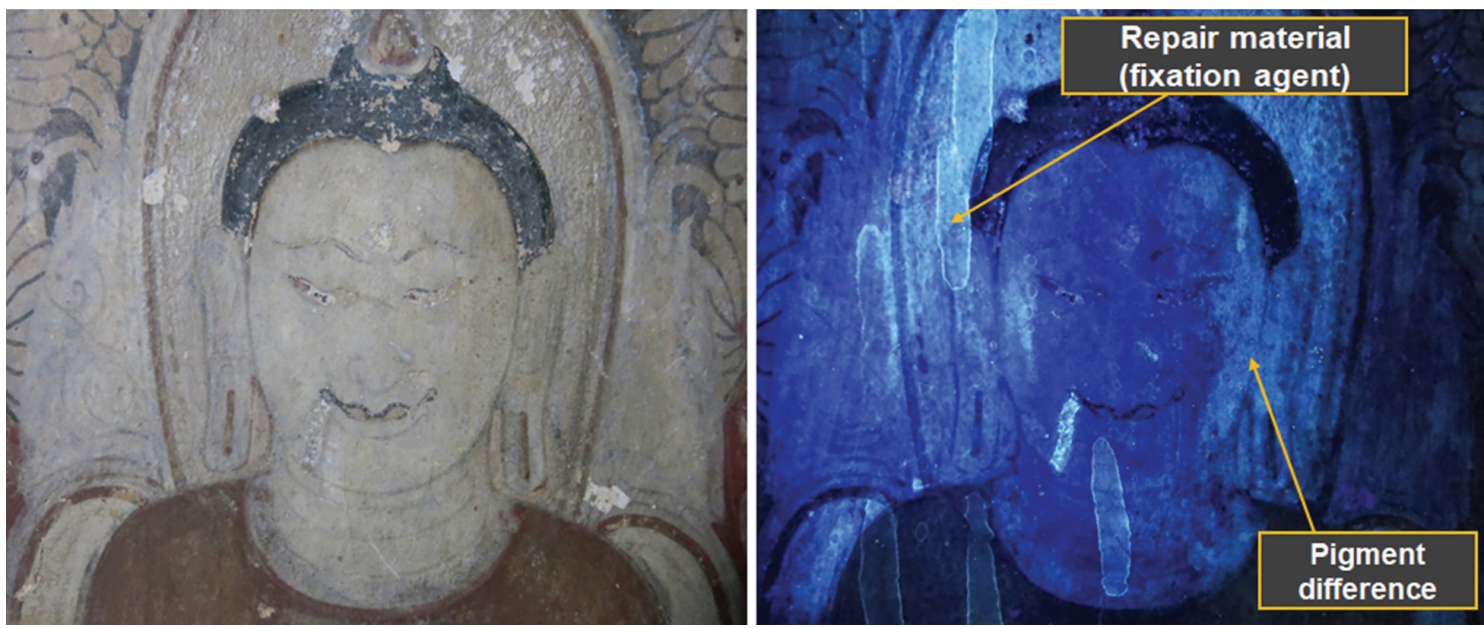

Figure 13. Images of the visible light(left) and the ultraviolet light(right)(\#477 main hall-south side).

as the reinforcing of the painting layer and removal of synthetic resin consolidation agents.

\subsection{Investigation of damages}

Eight types of damage types, viz. crack, delamination and exfoliation of the painting layer, uplift of the finishing layer, contamination, biological damage, water leak and artificial damage were assessed. Cracks were classified into fine cracks and cracks in the wall; damage in the colored layers was classified into delamination, exfoliation and discoloration; and contamination was classified into dust and soot, and presence of previous restoration materials(Figures 14 and 15).

The \#477 entrance hall, \#477 main hall, and \#478 entrance hall all displayed marked damage and contamination to the painting layer. All three areas showed severe damage, in the order of exfoliation of the finishing layer, cracks on the wall, and presence of previous restoration materials. Broken down 
by type, with the exception of the cracks, all other types of damage were identified with the level of severity in the order of \#477 entrance hall, \#477 main hall, and \#478 entrance hall.

When the status of damage is assessed comprehensively, the \#477 entrance hall showed a relatively high level of damage overall, while the \#478 entrance hall showed the least damage. As for the type of damage, all three areas showed the highest level of damage in the painting layer caused by peeling off, exfoliation, and contamination of the layer, followed by exfoliation of the finishing layer, and cracks on the wall. However, such results were determined based on information gathered in the process of optical survey of the surface of the mural. Thus, the following facts are to be clearly stated, that the structural and physical damage such as cracks and lifting of the wall may be inherent, when compared to the examination of physical properties on the mural surface, such as ultrasonic inspection.

Through the assessment of the conservation status of the mural, it was possible to objectively suggest that the painting layer and the wall require conservation treatment. In particular, through the inspection of physical properties on the surface and the damage map, it has been determined that the level of structural damage has aggravated and it is suggested that reinforcing work on the lifting and cracks is carried out on an urgent basis.
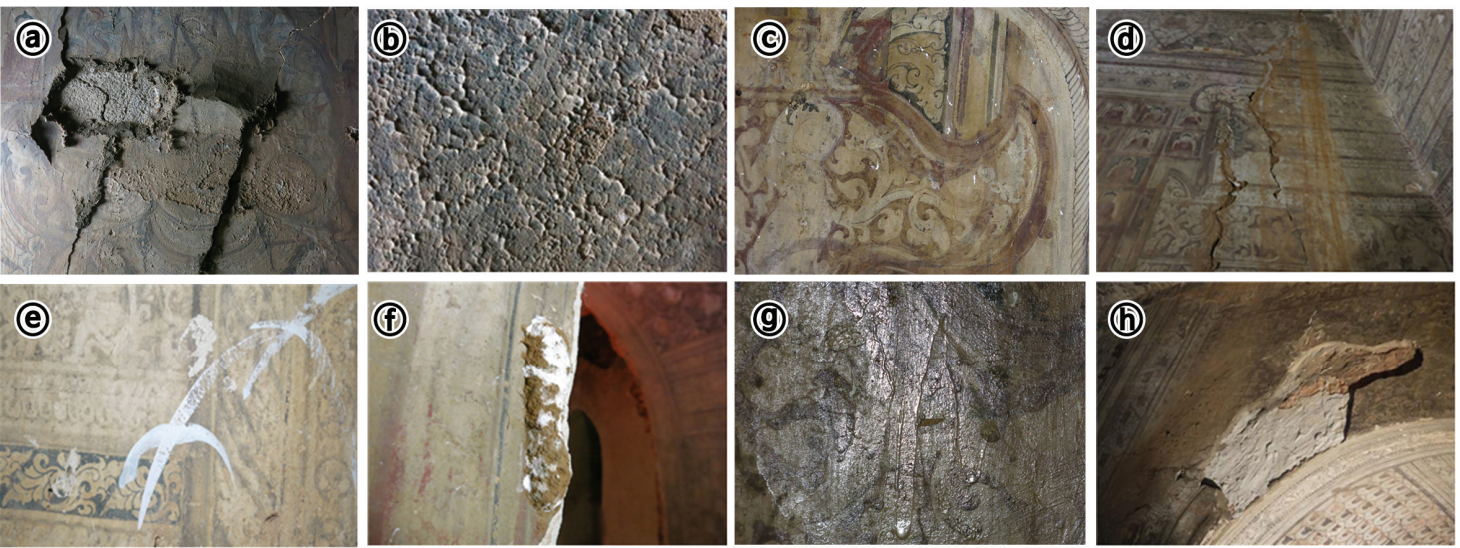

Figure 14. Types of damages in mural paintings in Payathonzu. (a) Crack, (b) Damages of painting layer, (c) Contamination, (d) Water leak, (e) Artificial damage, (f) Biological damage, (g) Previous repair material, (h) Exfoliation of finish layer.

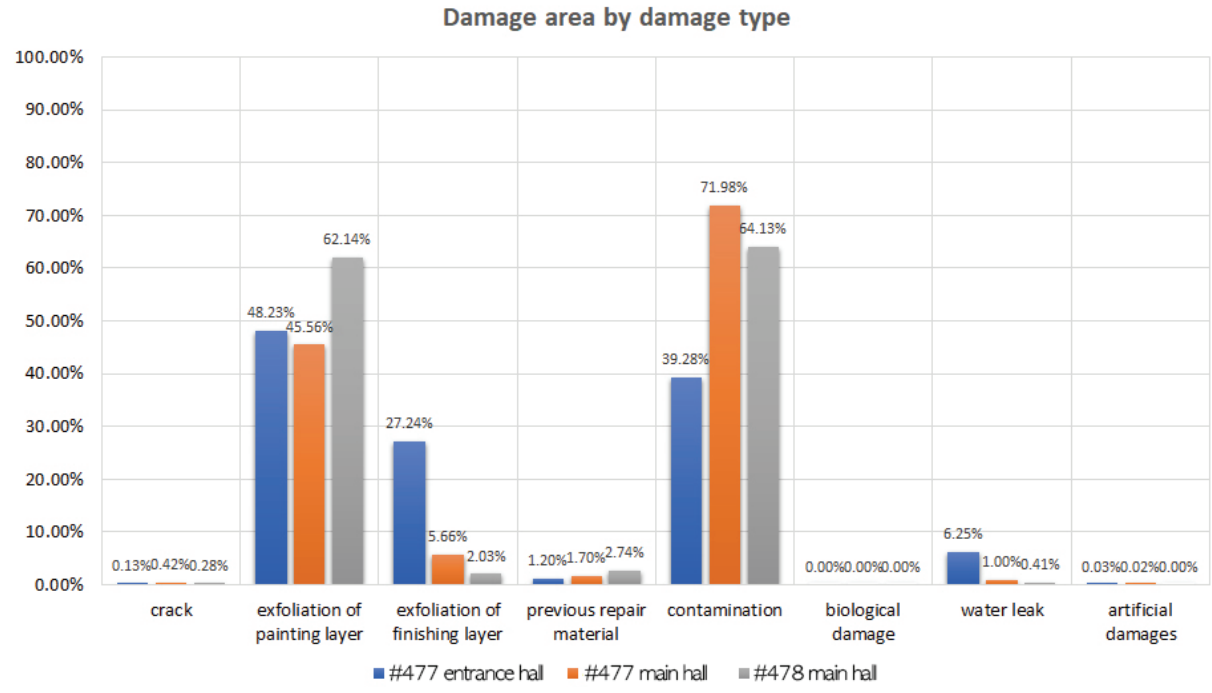

Figure 15. Damage rate by damage type. 


\section{CONCLUSION}

The diagnostic investigation into the conservation state of the Payathonzu temple mural, implemented by the present study, can be aggregated and summarized as follows.

First, as a result of optical survey, it was possible to definitely detect re-coated and contaminated portions of murals. Through the infrared inspection, it was possible to estimate circumstances where the modification or change of the original picture was made. Particularly, the ultraviolet investigation provided information that can be effectively used when removing synthetic resins.

At portions of conspicuously low ultrasonic speed values, it is judged that ultrasound is transmitted slowly due to wall crack or separation, compared with stable walls, and it can be considered that such portions are of low wall stability. The ultrasonic speed distribution map can provide objective information about cases where the physical properties of mural surface are low or require reinforcement work. From moisture measurement, it was confirmed that even murals of the same area may greatly differ in wall moisture contents according to locations, and it is judged that the locations of halls and the consequent conditions of temperature and humidity can affect the water contents of walls. In addition, through locations of high moisture content, it is possible to estimate the possibility of influence on mural damage. In conjunction with the results of wall diagnosis and damage state investigation, this can be used for the establishment of the cause of damage and for conservation and management.

As a result of consolidating the preservation status of the Payathonzu temple murals, peeling off, exfoliation, and contamination of the painting layer, cracks and breakage of the wall, separation of the wall stemming from the lifting of the wall were identified as the main types of damage. Particularly, the mural appeared vulnerable to damage caused by cracks and lifting and thus needed urgent restoration. Moreover, the application of fixing agents in the past resulted in excessive gloss, peeling off and exfoliation of parts of the painting layer. And it is judged that stabilization measures against this will be needed.

To sum up the results of diagnosing the state of conservation, temperature and humidity within the temple affect the water contents of walls. And it can be seen, from the assessment of damage state, that this has connection with damage to walls. Besides, it is presumed that several factors affect the conservation of murals and are revealed in aspects of damage. Therefore, it will be necessary to conduct research that establishes causes of damage through more diverse and careful analyses with respect to them. Among damage to painting layers of Payathonzu murals, it was found that contamination was severest. When excessive dust accumulates over a long period of time, it causes secondary damage including hydrolysis and biological attacks to the coloring layer by facilitating the adsorption of moisture, making its removal necessary. Besides the general contaminants, one of the elements that most gravely hinders the conservation of the coloring layer is adhesives used in the past. The investigation found that PVAc was the main synthetic resin adhesive used, that it was causing the coloring layer to crack and delaminate, and that it was harming the aesthetic aspect of the mural due to excessive gloss. The investigation concluded that stabilization was required for long-term conservation and that a basic technological review should be carried out with regards to said solution.

The major damages to the Payathonzu temple mural, specifically the cracking and separation in the wall, are a result of the heterogeneity between materials, and arise from a complication of factors including the surrounding environment, deformation of the mural structure, building load, and physical pressure from the surroundings. Some of the areas indicate a severe level of damage, and the existence of microcracks in the mural validate the judgement that damages will continue to occur. Therefore, reinforcing the damaged areas in the wall is an absolute necessity, which requires a thorough investigation and assessment into materials and technology along with experimentation using various material and techniques.

\section{ACKNOWLEDGEMENTS}

This research was carried out with as part of the investigation project of the Korea Cultural Heritage Foundation, "A study on the current state of temple murals of Bagan ruins and method of conserving mural paintings of Payathonzu temple". 


\section{REFERENCES}

Chae, S.J., Yang, H.J., Han, K.S., 2006, Nondestructive investigation of clay wall structure containing traditional mural paintings. -The clay walls having mural paintings housed in the protective building in Muwisa temple, Kangjin, Jeollanamde province-. Journal of Conservation Science, 18, 51-62. (in Korean with English abstract)

Haisung Cultural Heritage Conservation, 2019, A report on the scientific research of conservation state of mural paintings and the making of facsimile version in Buseoksa temple in Yeongju. (in Korean)

ICCROM, 1982, Mission report: Technical assistance for the conservation of the mural paintings and stuccoes at Pagan.

ICCROM, 1985, Conservation of mural paintings and stuccoes Pagan, Burma.

Jeong, H.Y. and Han, K.S., 2008, Study on the making wall techniques behind the Buddha in main building of Bongjeongsa temple. Journal of Conservation Science, 23, 53-65. (in Korean with English abstract)

Joo, K.M. and Kang, M.J., 2016, A study on Lokahteikpan temple in Bagan, Myanmmar. Journal of Buddhist Art, 21, 113-148. (in Korean with English abstract)

Korea Culture Heritage Foundation, Konkuk University, Chungbuk National University, 2018, A study on the current state of temple murals of Bagan ruins and methods of conserving mural paintings of Payathonzu temple.
Lee, H.S., 2016, Study on material characterization of earthen wall of Buddhist mural paintings in Joseon dynasty. Journal of Conservation Science, 32(1), 75-88. (in Korean with English abstract)

Lee, H.S., Kim, S.H. and Han, K.S., 2018a, Scientific investigation for conservation methodology of bracket mural paintings of Daeungjeon hall in Jikjisa temple. Journal of Conservation Science, 34(2), 107-118. (in Korean with English abstract)

Lee, H.S., Lee. H.H., Lee. K.M. and Han. K.S., 2014, Study on the manufacturing technology of mural tomb in Goa-dong of Daegaya period. Journal of Conservation Science, 30(4), 457-466. (in Korean with English abstract)

Lee, H.S., Lee, N.R. and Han, G.S., 2018b, Study on manufacturing techniques of bracket mural paintings of Daeungbojeon hall in Naesosa temple. Journal of Conservation Science, 34(6), 557-568. (in Korean with English abstract)

Lee, K.M., Lee, H.S. and Kim, M.J., 2012, Analysis and investigation of materials and Condition for Buddhist Wall Painting -Focusing on wall paintings of judgement hall in Jikji temple-. Journal of Buddhist Art, 14, 181-205. (in Korean with English abstract)

Lee, S.S. and Ahn, B.C., 2008, A pioneer in cultural preservation. Hanrim-won, Seoul, 145-159. (in Korean)

UNESCO, 1994, Conservation of mural paintings and external stuccoes, Pagan, union of Myanmar. 